\title{
Effect of $T$ helper cell 1/T helper cell 2 balance and nuclear factor- $\kappa B$ on white matter injury in premature neonates
}

\author{
XUEWEN SU ${ }^{1 *}$, HAIFENG YUAN ${ }^{1 *}$, HONGWEI CUI $^{2}$, HUA ZHU $^{1}$, \\ XIA YUN ${ }^{1}$, WENYAN TANG ${ }^{3}$, JUNLONG CHEN ${ }^{1}$ and ZU LUAN ${ }^{4}$ \\ ${ }^{1}$ Department of Paediatrics, Inner Mongolia People's Hospital, Huhehot, Inner Mongolia 010017; ${ }^{2}$ Department of \\ Paediatrics, Clinical Medical Research Center, Affiliated Hospital of Inner Mongolia Medical University, Huhehot, \\ Inner Mongolia 010010; ${ }^{3}$ Department of Paediatrics, Affiliated Navy General Hospital of Southern Medical University, \\ Haidian, Beijing 100048; ${ }^{4}$ Department of Paediatrics, An Hui Provincial Hospital, Hefei, Anhui 230001, P.R. China
}

Received October 17, 2016; Accepted June 8, 2017

DOI: $10.3892 / \mathrm{mmr} .2018 .8511$

\begin{abstract}
Incidence of white matter injury (WMI), which is featured as softening of white matter tissues, has recently increased. Previous studies have demonstrated a close correlation between $\mathrm{T}$ helper cell 1 and T helper cell 2 (Th1/Th2) imbalance and nuclear factor- $\kappa \mathrm{B}(\mathrm{NF}-\kappa \mathrm{B})$ with brain disease. Their role in premature WMI, however, remains to be illustrated. Serum samples were collected from 60 premature WMI neonates, plus another control group of 60 premature babies without WMI. Patients were further divided into mild, moderate and severe WMI groups. Reverse transcription quantitative polymerase chain reaction was used to test mRNA expression levels of Th1/Th2 cytokines, including interleukin 2 (IL)-2, tumor necrosis factor- $\alpha$ (TNF- $\alpha$ ), IL-4, IL-10 and nuclear factor (NF)- $\kappa \mathrm{B}$, whilst their serum levels were measured by ELISA. Their correlation with disease occurrence and progression were further analysed, to illus-

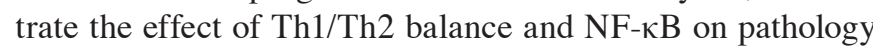
of premature WMI. Serum levels of IL-4 and IL-10 were significantly decreased in premature WMI babies, whilst IL-2, TNF- $\alpha$ and NF- $\kappa$ B were upregulated $(\mathrm{P}<0.05$ vs. control group). With aggravated disease, IL-4 and IL-10 expression was further decreased while IL-2, TNF- $\alpha$ and NF- $\kappa$ B were increased ( $\mathrm{P}<0.05$ vs. mild WMI group). Th1 cytokines IL-2 and TNF- $\alpha$ and NF- $\kappa$ B were negatively correlated with Th2 cytokines IL-4 and IL-10. Disease severity was positively correlated with IL-2, TNF- $\alpha$ and NF- $\kappa$ B expression, and was negatively correlated with IL-4 and IL-10 ( $<<0.05)$. Th1/Th2
\end{abstract}

Correspondence to: Dr Hua Zhu, Department of Paediatrics, Inner Mongolia People's Hospital, 20 Zhaowuda Road, Saihan, Huhehot, Inner Mongolia 010017, P.R. China

E-mail: zuoluanasd@sina.com

*Contributed equally

Key words: premature baby, white matter injury, cytokines, $\mathrm{T}$ helper cell 1, T helper cell 2 imbalance and $\mathrm{NF}-\kappa \mathrm{B}$ upregulation were observed in WMI pathogenesis, with elevated secretion of Th1 cytokines and decreased Th2 cytokines, suggesting that Th1/Th2 imbalance and $\mathrm{NF}-\kappa \mathrm{B}$ upregulation may be a potential indicator for the early diagnosis and treatment of WMI pathogenesis and progression.

\section{Introduction}

Due to the development of obstetrical techniques and perinatal medicine, and advancement of neonatal intensive care, the survival rate of premature babies has been increased over the years $(1,2)$. Associated complications, however, are also rising, particularly in brain injuries (3). The incidence of neonatal brain injury occurs in $>10 \%$ of all premature babies (4). Neonatal white matter injury (WMI) is a common type of brain injury in premature babies. Pathological features of WMI include abundant infiltration of microglia, damaged oligodendrocytes, formation of astrocytes, myelin damage and axonal injury. A severe manifestation is the softening of white matter around ventricular zones $(5,6)$. Neonatal WMI is accompanied with neurological injury and neurodevelopment retardation to different extents (7). Severe WMI can cause intelligence and body development disorder, epilepsy, visual-auditory disorder and cerebral palsy, contributing to perinatal mortality and becoming a public health issue worldwide $(8,9)$. Multiple factors can induce premature WMI, including intra-uterus infection, hypoxia, cerebral ischemia and fetal age (9). However, due to insufficient knowledge of WMI pathogenesis, currently no effective treatment exists, leaving only symptomatic treatment with unfavorable efficacy (10). Therefore, studying WMI pathogenesis should draw attention in pediatric and obstetric fields.

T helper cells (Th) can be divided into 2 subgroups, namely Th1 and Th2 cells (11). A recent study demonstrated the cross-regulation and inhibition between Th1 and Th2 cells via modulating cytokine secretion, further maintaining Th1-Th2 balance, and exerting important functions for the normal immune functions of the body (12). Th1 cells mainly secrete interleukin (IL)-2 and tumor necrosis factor- $\alpha$ (TNF- $\alpha$ ), while Th2 cells secrete IL-4 and IL-10 (13). Th1/Th2 can maintain a 
homeostatic condition via self-regulation and cross-regulation targeting secreted cytokines, and it participates in the modulation of cellular and humoral immunity. As a member of transcriptional factor protein family, $\mathrm{NF}-\kappa \mathrm{B}$ participates in regulating cytokine secretion, and inflammatory or immune responses $(14,15)$. A previous study demonstrated the close association between Th1-biased Th cell transition, plus the secretary level of body cytokines and abnormal expression of nuclear factor (NF)- $\kappa \mathrm{B}$ and the occurrence of cerebral injury (16). The current study investigated the expression profile of Th1 and Th2 cytokines in WMI patients, in an attempt to illustrate the role and functions of Th1/Th1 alternation in WMI pathogenesis.

\section{Patients and methods}

General information. A total of 60 premature neonatal babies diagnosed with WMI were recruited from the Inner Mongolia People's Hospital (Huhehot, Inner Mongolia) from December 2014 to June 2015. There were 33 males and 27 females (gestation, 28-34 weeks; average gestation, 30 \pm 2 weeks; body weight at birth, 1,000-2,500 g; average (mean) body weight, $1,820 \pm 350 \mathrm{~g}$ ). WMI was diagnosed by head ultrasound, which was performed by at least two pediatric consultants.

The exclusive criteriaincluded: Perinatal infection, asphyxia, circulating disorder or ion disorder, those with severe kidney/liver dysfunction, inherited metabolic disorder, major malformation of organs, placental abruption, intra-uterus fetal distress and premature rupture of fetal membranes. The control group included 60 premature neonatal babies without WMI, recruited during the same period. The average gestation period was $31 \pm 2$ weeks (range, 28-35 weeks), including 22 males and 27 females, with an average body weight at birth of $1,790 \pm 420 \mathrm{~g}$ (range, 1,000-2,500 g). No statistically significant difference was observed between the two groups regarding body weight. This study was approved by the ethical committee of the Inner Mongolia People's Hospital. Written informed consents were obtained by legal guardians for all participants.

Reagents and equipment. TRIzol reagent, an RNA extraction kit, reverse transcription-quantitative polymerase chain reaction (RT-qPCR) primers, an RT-qPCR kit were all purchased from Invitrogen; Thermo Fisher Scientific, Inc. (Waltham, MA, USA). ELISA kits for IL-2 (cat. no. BMS221-2), TNF- $\alpha$ (cat. no. 88-7346-22), IL-4 (cat. no. BMS225-2), IL-10 (cat. no. BMS215-2) and NF- $\mathrm{BB}$ (cat. no. KHO0371) were purchased from eBioscience (Thermo Fisher Scientific, Inc.). A lab system version 1.3.1 micro plate reader was purchased from Bio-Rad Laboratories, Inc. (Hercules, CA, USA). Cell culture incubator was purchased from Suzhou Purification Engineering Installation Co., Ltd. (Suzhou, China). A real time PCR cycler was purchased from Applied Biosystems; Thermo Fisher Scientific, Inc. A UV spectrophotometer was purchased from Mettler-Toledo (Greifensee, Switzerland).

Grouping of WMI patients. Grade of disease was classified into mild [minor reduction of white matter, perturbation of adjacent groves but no ventricular dilation, small and limited high-low signal on magnetic resonance imaging (MRI)], moderate (significantly decreased white matter leaving little white matter between lateral ventricles and gray matter, accompanied with dilation of lateral ventricles) and severe (replacement of white matter by cystic tissues, significantly high signal fusion with lateral ventricle under weighted images and significantly dilated ventricles), based on Flodmar standard and MRI results (17). There were 17, 25 and 18 cases of mild, moderate and severe diseases, respectively.

Sample collection. Blood samples $(5 \mathrm{ml})$ were collected from veins of both disease and control groups $24 \mathrm{~h}$ within admitting to the hospital. Blood samples were centrifuged at 3,000 x g for $15 \mathrm{~min}$ at room temperature to collect serum, which was frozen at $-80^{\circ} \mathrm{C}$.

RT-qPCR for the expression profile of Th1/Th1 cytokines in WMI patients. TRIzol reagent was used to extract total RNA from peripheral blood. RNA purity and concentration were determined by UV spectrometry. Reverse transcription was performed using a test kit. cDNA was synthesized with specific primers designed using PrimerPremier 6.0 (www.premierbiosoft.com/primerdesign). RT-qPCR was used to test target gene expression using specific primers (Table I) synthesized by Sangon Biotech Co., Ltd., under the following conditions: $52^{\circ} \mathrm{C}$ for $1 \mathrm{~min}$, followed by 35 cycles each containing $90^{\circ} \mathrm{C}$ for $30 \mathrm{sec}, 58^{\circ} \mathrm{C}$ for $50 \mathrm{sec}$ and $72^{\circ} \mathrm{C}$ for $35 \mathrm{sec}$. Fluorescent PCR was used to collect all data. Cq values were calculated using the $G A P D H$ gene as the internal reference to plot a standard curve, on which quantitative analysis was performed using the $2^{-\Delta \Delta C q}$ method (18).

Serum levels of Th1/Th2 cytokines and NF- $\kappa B$ in WMI patients by ELISA. All samples were measured for Th1/Th2 cytokines including IL-2, TNF- $\alpha$, IL-4, IL-10 and NF- $\kappa \mathrm{B}$, using ELISA kits according to manufacturer's protocol. Linear regression function was plotted based on standard concentration and optical density (OD) values. Sample concentration was deduced on the linear function according to OD values.

Statistical analysis. All data were analysed using SPSS 22.0 software for statistical analysis (IBM Corp., Armonk, NY, USA). At least three independent experiments were performed for each assay. Data are presented as the mean \pm standard deviation. Comparison of means among multiple groups was performed by one-way analysis of variance with Newman-Keuls multiple comparison post hoc analysis. Student's t-test was used to compare two groups. Pearson analysis was used for correlation analysis. $\mathrm{P}<0.05$ was considered to indicate a statistically significant difference.

\section{Results}

$m R N A$ expression level of the Thl cytokines $I L-2$ and TNF- $\alpha$. RT-qPCR was used to test the mRNA expression levels of the Th1 cytokines IL- 2 and TNF- $\alpha$ in all groups. Significantly elevated IL-2 and TNF- $\alpha$ mRNA levels were observed in WMI patients $(\mathrm{P}<0.05$ vs. control group). With aggravated disease condition, the mRNA expression levels of IL-2 and TNF- $\alpha$ were further potentiated $(\mathrm{P}<0.05$ vs. mild patients, Fig. 1). 
Table I. Primer sequences.

Gene

Forward primer $5^{\prime}-3^{\prime}$

Reverse primer 5'-3'

\begin{tabular}{ll} 
GADPH & AGTGCCAGCCTCGTCTCATAG \\
IL-2 & GATCTACGCAGCGAAGAACTT \\
TNF- $\alpha$ & CTACGGAAGATCTCAATAGCG \\
IL-4 & AGCGGATCTACGGAACTCAAT \\
IL-10 & GAAGATCTCAATAGCGTCA \\
NF- $-\mathrm{B}$ & TCGCGGATCTACGGAAC \\
\hline
\end{tabular}

IL, interleukin; TNF- $\alpha$, tumor necrosis factor- $\alpha$; NF- $\kappa B$, nuclear factor- $\kappa \mathrm{B}$.

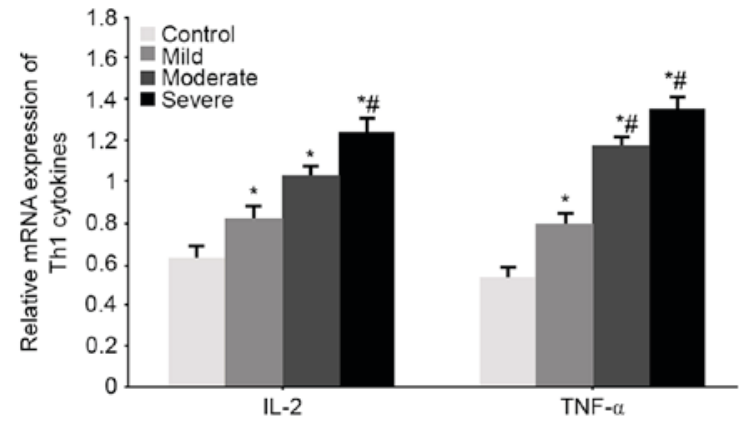

Figure 1. mRNA expression levels of the Th1 cytokines IL-2 and TNF- $\alpha$ Data are expressed as the mean \pm standard deviation. ${ }^{*} \mathrm{P}<0.05$ vs. control group; ${ }^{\#} \mathrm{P}<0.05$ vs. mild group. Th1, T helper cell 1; IL-2, interleukin-2; TNF- $\alpha$, tumor necrosis factor- $\alpha$. Three independent experiments were performed for each group.

mRNA expression of the Th2 cytokines IL-4 and IL-10 mRNA expression in WMI patients. RT-qPCR was used to test the mRNA expression levels of the Th2 cytokines IL-4 and IL-10 in all groups. Significantly decreased IL-4 and IL-10 mRNA expression levels were observed in WMI patients $(\mathrm{P}<0.05$ vs. control group). With aggravated disease condition, the mRNA expression levels of IL-4 and IL-10 were further decreased $(\mathrm{P}<0.05$ vs. mild patients, Fig. 2).

Serum levels of Th1 cytokines IL-2 and TNF- $\alpha$ in WMI neonates. ELISA was used to measure serum levels of the Th1 cytokines IL-2 and TNF- $\alpha$ in all WMI neonates. The results were similar results to the mRNA ones, as significantly elevated serum IL-2 and TNF- $\alpha$ levels were observed in WMI patients $(\mathrm{P}<0.05$ vs. control group). With aggravated disease condition, serum levels of IL-2 and TNF- $\alpha$ were further potentiated $(\mathrm{P}<0.05$ vs. mild patients, Fig. 3$)$.

Serum levels of Th2 cytokines IL-4 and IL-10 in WMI neonates. ELISA was used to measure serum levels of the Th2 cytokines IL-4 and IL-10 in all WMI neonates. The results were similar results to the mRNA ones, as significantly lowered serum IL-4 and IL-10 levels were observed in WMI patients ( $\mathrm{P}<0.05$ vs. control group). With aggravated disease condition, serum level of IL-4 and IL-10 was further suppressed ( $\mathrm{P}<0.05$ vs. mild patients, Fig. 4).

$m R N A$ and protein expression of $N F-\kappa B$ in serum of WMI premature neonates. RT-qPCR and ELISA were used to

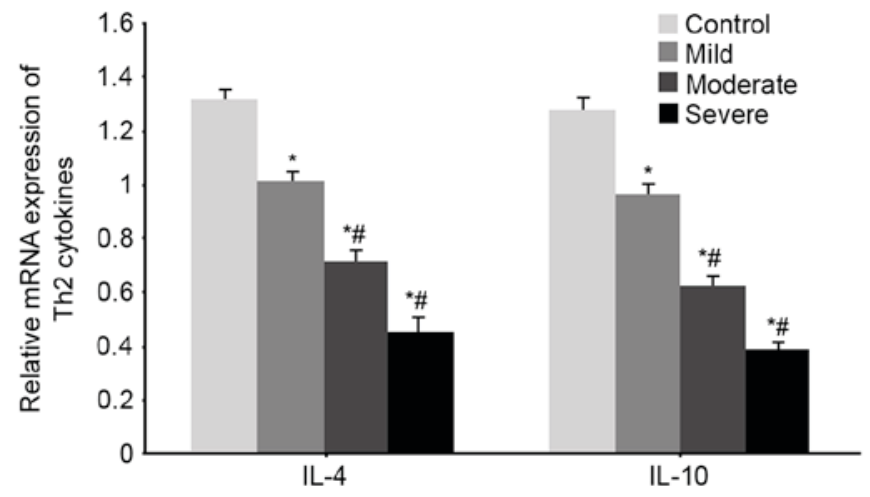

Figure 2. mRNA expression levels of the Th2 cytokines IL-4 and IL-10. Data are expressed as the mean \pm standard deviation. ${ }^{*} \mathrm{P}<0.05$ vs. control group; ${ }^{~} \mathrm{P}<0.05$ vs. mild group. Th2, T helper cell 2; IL, interleukin; TNF- $\alpha$, tumor necrosis factor- $\alpha$. Three independent experiments were performed for each group.

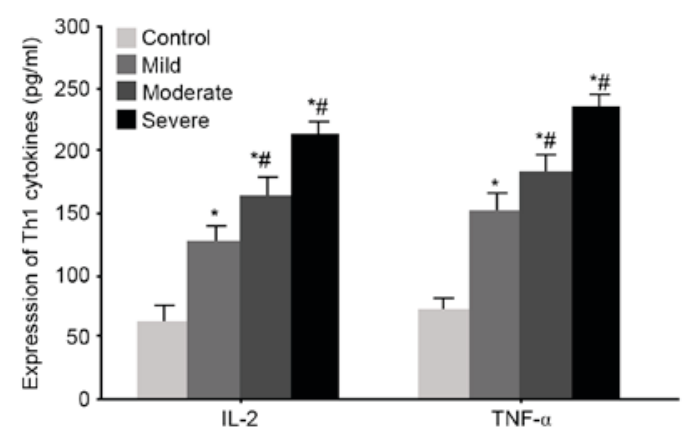

Figure 3. Serum levels of the Th1 cytokines IL-2 and TNF- $\alpha$. Data are expressed as the mean \pm standard deviation. ${ }^{~} \mathrm{P}<0.05$ vs. control group; ${ }^{\prime} \mathrm{P}<0.05$ vs. mild group. Th1, T helper cell 1; IL-2, interleukin-2; TNF- $\alpha$, tumor necrosis factor- $\alpha$. Three independent experiments were performed for each group.

analyse the mRNA and protein expression profiles of $\mathrm{NF}-\kappa \mathrm{B}$ in premature neonates with WMI, respectively. Significantly elevated NF- $\kappa \mathrm{B}$ mRNA expression levels were observed in patients $(\mathrm{P}<0.05$ vs. control group, Fig. 5). With aggravated disease condition, $\mathrm{NF}-\kappa \mathrm{B}$ mRNA expression levels were further elevated $(\mathrm{P}<0.05$ vs. mild group, Fig. 5). Similar to those of mRNA, serum NF- $\kappa$ B levels were significantly elevated in the disease group, and in the severe sub-group ( $\mathrm{P}<0.05$, Fig. 6).

Correlation between serum Th1 and Th2 cytokines and $N F-\kappa B$ in WMI neonates. The correlation between Th1 and 


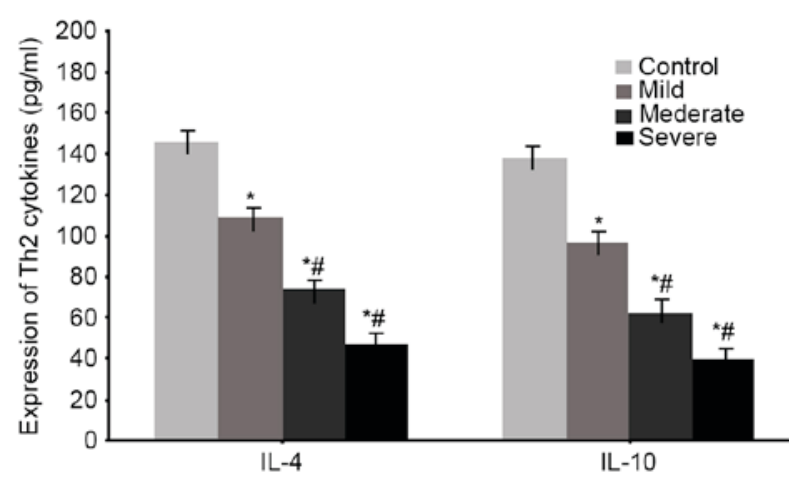

Figure 4. Serum levels of the Th2 cytokines IL-4 and IL-10. Data are expressed as the mean \pm standard deviation. ${ }^{*} \mathrm{P}<0.05$ vs. control group; ${ }^{\text {"}} \mathrm{P}<0.05$ vs. mild group. Th2, T helper cell 2; IL-4, interleukin- 4 ; IL-10, interleukin-10. Three independent experiments were performed for each group.

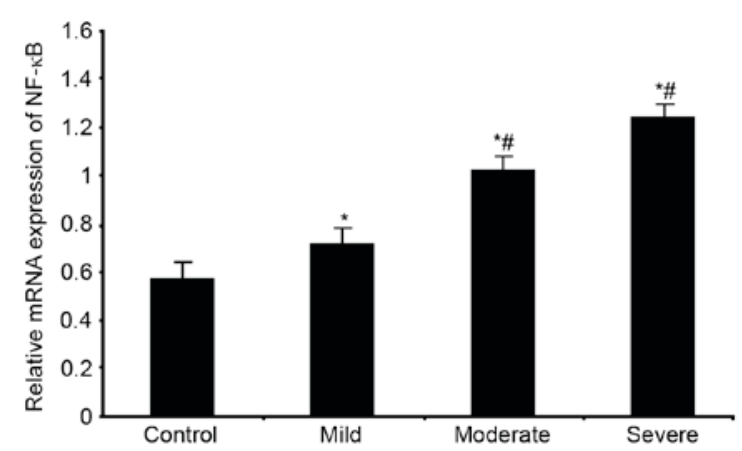

Figure 5. NF- $\mathrm{kB}$ mRNA expression levels in white matter injury premature neonates. Data are expressed as the mean \pm standard deviation. ${ }^{~} \mathrm{P}<0.05$ vs. control group; ${ }^{*} \mathrm{P}<0.05$ vs. mild group. NF- $\mathrm{kB}$, nuclear factor- $\kappa \mathrm{B}$. Three independent experiments were performed for each group.

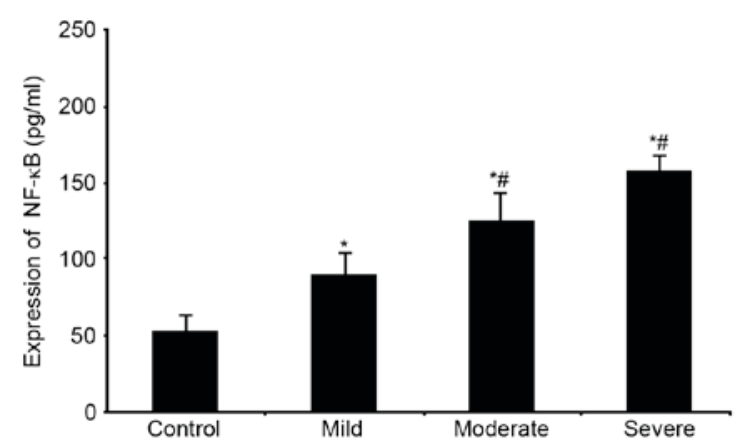

Figure 6. Serum NF- $\kappa B$ levels in white matter injury premature neonates. Data are expressed as the mean \pm standard deviation. ${ }^{*} \mathrm{P}<0.05$ vs. control group; ${ }^{~} \mathrm{P}<0.05$ vs. mild group. NF- $\kappa \mathrm{B}$, nuclear factor- $\mathrm{\kappa} \mathrm{B}$. Three independent experiments were performed for each group.

Th2 cytokines in serum of WMI patients was further analysed. The results demonstrated that IL-2, TNF- $\alpha$ and NF- $\kappa$ B were negatively correlated with IL-4 and IL-10 ( $\mathrm{P}<0.05$, Table II).

Correlation between serum Th1/Th2 cytokines and $N F-\kappa B$ and disease severity. The correlation between Th1/Th2 cytokines in the serum of WMI patients and their disease severity was further analysed. The results demonstrated that IL-2, TNF- $\alpha$ and NF- $\kappa$ B expression were positively correlated with disease severity, whilst IL-4 and IL-10 expression
Table II. Correlation between serum Th1 and Th2 cytokines and $\mathrm{NF}-\kappa \mathrm{B}$ in WMI patients.

\begin{tabular}{lcccc}
\hline Cytokines & IL-4 & P-value & IL-10 & P-value \\
\hline IL-2 & -0.731 & $<0.05$ & -0.736 & $<0.05$ \\
TNF- $\alpha$ & -0.657 & $<0.05$ & -0.622 & $<0.05$ \\
NF- $\kappa$ B & -0.867 & $<0.05$ & -0.726 & $<0.05$ \\
\hline
\end{tabular}

Th, T helper cell; NF- $\kappa \mathrm{B}$, nuclear factor- $\mathrm{B}$; WMI, white matter injury; IL, interleukin; TNF- $\alpha$, tumor necrosis factor- $\alpha$.

Table III. Correlation between serum Th1/Th2 cytokines and disease severity.

Cytokines Mild P-value Moderate P-value Severe P-value

\begin{tabular}{lrrrrrr}
\hline NF- $к B$ & 0.697 & $<0.05$ & 0.765 & $<0.05$ & 0.812 & $<0.05$ \\
IL-2 & 0.815 & $<0.05$ & 0.436 & $<0.05$ & 0.702 & $<0.05$ \\
TNF- $\alpha$ & 0.958 & $<0.05$ & 0.516 & $<0.05$ & 0.639 & $<0.05$ \\
IL-4 & -0.479 & $<0.05$ & -0.679 & $<0.05$ & -0.815 & $<0.05$ \\
IL-10 & -0.652 & $<0.05$ & -0.581 & $<0.05$ & -0.562 & $<0.05$
\end{tabular}

Th, T helper cell; NF-кB, nuclear factor- $\kappa \mathrm{B}$; IL, interleukin; TNF- $\alpha$, tumor necrosis factor- $\alpha$.

were negatively correlated with disease severity $(\mathrm{P}<0.05$, Table III).

\section{Discussion}

A complicated pathogenesis mechanism exists for WMI in neonates. Intra-uterine factors and ischemia-reperfusion are two major determinants of WMI (19). In an intra-uterus infection model by LPS injection, and another neonatal mouse model of hypoxia-ischemia, ventricular dilation, significant diffused WMI and softening lesion in cerebral white matter can be observed (20). In the intra-uterus infection model, inflammatory cytokines including TNF- $\alpha$, IL- 6 and interferon- $\gamma$ are elevated, in addition to an altered cytokine network in the uterus of pregnant mice (21). This indicates a possible role of Th1/Th2 in WMI pathogenesis. The change of Th1/Th2 balance and $\mathrm{NF}-\kappa \mathrm{B}$ are closely correlated with occurrence of cerebral injury. The role of Th1/Th2 imbalance and $\mathrm{NF}-\kappa \mathrm{B}$, however, remains to be illustrated. The same stands for the underlying mechanisms.

Among various factors secreted by Th1 cells, TNF- $\alpha$ and IL-2 are two representative cytokines. Hypoxia and ischemia cause elevated number of Th1 cells, leading to enhanced secretion of TNF- $\alpha$ and IL-2, causing chronic inflammation. Therefore, elevated secretion of Th1-associated cytokines is an important factor during inflammation. When the body is under inflammatory change, abundant activation of inflammatory and immune-associated genes occur, inducing elevated expression of cytokines including TNF- $\alpha$ and IL-2, thus modulating a complex cytokine network inside the body (22). $\mathrm{NF}-\kappa \mathrm{B}$ is a transcription factor widely distributed in eukaryotic 
cells, governing multiple pathological processes including inflammation, immune response, cell apoptosis and proliferation (23). The present study demonstrated significantly higher mRNA and protein expression levels of TNF- $\alpha$ and IL-2 in WMI patients compared with the control group. With further aggravation of disease severity, TNF- $\alpha$ and IL-2 levels were further elevated. IL-4 and IL-10 were further suppressed with advanced disease condition. A correlation analysis between $\mathrm{Th} 1 / \mathrm{Th} 2$ cytokines in WMI patients revealed a negative correlation between TNF- $\alpha$ and IL-2, and Il-4 and IL-10. Disease severity was positively correlated with TNF- $\alpha$ and IL-2 expression, and was negatively correlated with IL-4 and IL-10. These results demonstrated that the facilitation of secretion of the inflammatory factors TNF- $\alpha$ and IL-2 could activate the inflammatory response, leading to leukocyte adhesion, maturation and migration of immune cells, which might lead to further progression of inflammation, eventually leading to death of oligodendrocytes, impairing myelination in the central nervous system, and further severity of WMI (24). Cytokines released by Th1 and Th2 cells can antagonize each other and inhibit Th response and release of associated factors, thus enhancing the humoral immune response and exerting protective roles (25). NF- $\kappa B$ activation leads to elevated expression of inflammatory factors, especially the Th1-secreted cytokines TNF- $\alpha$ and IL-2, suggesting a positive feedback loop mechanism of TNF- $\alpha$ for secretion of inflammatory factors (25). During WMI pathogenesis, NF- $\kappa \mathrm{B}$ upregulation increases secretion of TNF- $\alpha$ and IL-2, both of which inhibit secretion of IL-4 and IL-10, leading to Th1/Th2 imbalance, and making a pathological progression of WMI. Therefore, the present study provided evidence for studying WMI pathogenesis.

In conclusion, during WMI pathogenesis, NF- $\mathrm{kB}$ upregulation increases the secretion of Th1 cytokines and decreases the secretion of Th 2 cytokines, causing Th1/Th2 imbalance, which may be a potential risk marker for the early detection or treatment of WMI.

\section{References}

1. Pagnozzi AM, Dowson N, Doecke J, Fiori S, Bradley AP Boyd RN and Rose S: Automated, quantitative measures of grey and white matter lesion burden correlates with motor and cognitive function in children with unilateral cerebral palsy. Neuroimage Clin 11: 751-759, 2016.

2. Zhang Z, Bassam B, Thomas AG, Williams M, Liu J, Nance E, Rojas C, Slusher BS and Kannan S: Maternal inflammation leads to impaired glutamate homeostasis and up-regulation of glutamate carboxypeptidase II in activated microglia in the fetal/newborn rabbit brain. Neurobiol Dis 94: 116-128, 2016.

3. Li J, Yawno T, Sutherland A, Loose J, Nitsos I, Bischof R, Castillo-Melendez M, McDonald CA, Wong FY, Jenkin G and Miller SL: Preterm white matter brain injury is prevented by early administration of umbilical cord blood cells. Exp Neurol 283: 179-187, 2016.

4. Sandhu MS, Ross HH, Lee KZ, Ormerod BK, Reier PJ and Fuller DD: Intraspinal transplantation of subventricular zone-derived neural progenitor cells improves phrenic motor output after high cervical spinal cord injury. Exp Neurol 287: 205-215, 2017.

5. Stetler RA, Gao Y, Leak RK, Weng Z, Shi Y, Zhang L, Pu H, Zhang F, Hu X, Hassan S, et al: APE1/Ref-1 facilitates recovery of gray and white matter and neurological function after mild stroke injury. Proc Natl Acad Sci USA 113: E3558-E3567, 2016.

6. Ceschin R, Lee VK, Schmithorst V and Panigrahy A: Regional vulnerability of longitudinal cortical association connectivity: Associated with structural network topology alterations in preterm children with cerebral palsy. Neuroimage Clin 9: 322-337, 2015.
7. Serdar M, Herz J, Kempe K, Lumpe K, Reinboth BS, Sizonenko SV, Hou X, Herrmann R, Hadamitzky M, Heumann R, et al: Fingolimod protects against neonatal white matter damage and long-term cognitive deficits caused by hyperoxia. Brain Behav Immun 52: 106-119, 2016.

8. Cheng I, Miller SP, Duerden EG, Sun K, Chau V, Adams E, Poskitt KJ, Branson HM and Basu A: Stochastic process for white matter injury detection in preterm neonates. Neuroimage Clin 7: 622-630, 2015

9. Ranchhod SM, Gunn KC, Fowke TM, Davidson JO, Lear CA, Bai J, Bennet L, Mallard C, Gunn AJ and Dean JM: Potential neuroprotective strategies for perinatal infection and inflammation. Int J Dev Neurosci 45: 44-54, 2015.

10. Bentzley JP, Coker-Bolt P, Moreau NG, Hope K, Ramakrishnan V, Brown T, Mulvihill D and Jenkins D: Kinematic measurement of 12-week head control correlates with 12-month neurodevelopment in preterm infants. Early Hum Dev 91: 159-164, 2015.

11. Tian T, Yu S, Liu L, Xue F, Yuan C, Wang M, Ji C and Ma D: The profile of $\mathrm{T}$ helper subsets in bone marrow microenvironment is distinct for different stages of acute myeloid leukemia patients and chemotherapy partly ameliorates these variations. PLoS One 10: e0131761, 2015.

12. Vargas-Rojas MI, Solleiro-Villavicencio H and Soto-Vega E: Th1, Th2, Th17 and Treg levels in umbilical cord blood in preeclampsia. J Matern Fetal Neonatal Med 29: 1642-1645, 2016.

13. Song KH, Kim MH, Kang SM, Jung SY, Ahn J, Woo HJ, Nam SY, Hwang SG, Ryu SY and Song JY: Analysis of immune cell populations and cytokine profiles in murine splenocytes exposed to whole-body low-dose irradiation. Int J Radiat Biol 91: 795-803, 2015.

14. Kornete M, Mason ES, Girouard J, Lafferty EI, Qureshi S and Piccirillo CA: Th1-Like ICOS+ Foxp3+ treg cells preferentially express CXCR 3 and home to $\beta$-Islets during pre-diabetes in BDC2.5 NOD mice. PLoS One 10: e0126311, 2015.

15. Wang J, Cao H, Wang H, Yin G, Du J, Xia F, Lu J and Xiang M: Multiple mechanisms involved in diabetes protection by lipopolysaccharide in non-obese diabetic mice. Toxicol Appl Pharmacol 285: 149-158, 2015.

16. Kong F, Zhang W, Feng B, Zhang H, Rao H, Wang J, Cong X and Wei L: Abnormal CD4 + T helper (Th)1 cells and activated memory B cells are associated with type III asymptomatic mixed cryoglobulinemia in HCV infection. Virol J 12: 100, 2015.

17. Whitaker AH, Feldman JF, Lorenz JM, McNicholas F, Fisher PW, Shen S, Pinto-Martin J, Shaffer D and Paneth N: Neonatal head ultrasound abnormalities in preterm infants and adolescent psychiatric disorders. Arch Gen Psychiatry 68: 742-752, 2011.

18. Livak KJ and Schmittgen TD: Analysis of relative gene expression data using real-time quantitative PCR and the 2(-Delta Delta C(T)) method. Methods 25: 402-408, 2001.

19. Constable RT, Ment LR, Vohr BR, Kesler SR, Fulbright RK, Lacadie C, Delancy S, Katz KH, Schneider KC, Schafer RJ, et al: Prematurely born children demonstrate white matter microstructural differences at 12 years of age, relative to term control subjects: An investigation of group and gender effects. Pediatrics 121: 306-316, 2008.

20. Woodward LJ, Edgin JO, Thompson D and Inder TE: Object working memory deficits predicted by early brain injury and development in the preterm infant. Brain 128: 2578-2587, 2005.

21. Anand G, Vasanthakumar R, Mohan V, Babu S and Aravindhan V: Increased IL-12 and decreased IL-33 serum levels are associated with increased Th1 and suppressed Th2 cytokine profile in patients with diabetic nephropathy (CURES-134). Int J Clin Exp Pathol 7: 8008-8015, 2014.

22. Zabetian-Targhi F, Mirzaei K, Keshavarz SA and Hossein-Nezhad A: Modulatory role of omentin-1 in inflammation: Cytokines and dietary intake. J Am Coll Nutr 35: 670-678, 2016.

23. Lee CH, Park JH, Ahn JH and Won MH: Effects of melatonin on cognitive impairment and hippocampal neuronal damage in a rat model of chronic cerebral hypoperfusion. Exp Ther Med 11: 2240-2246, 2016

24. Coomes SM, Pelly VS, Kannan Y, Okoye IS, Czieso S, Entwistle LJ, Perez-Lloret J, Nikolov N, Potocnik AJ, Biró J, et al: IFN $\gamma$ and IL-12 restrict Th2 responses during helminth/plasmodium co-infection and promote IFN $\gamma$ from Th2 cells. PLoS Pathog 11: e1004994, 2015.

25. Wang TY, Lee SY, Chen SL, Chang YH, Wang LJ, Chen PS, Chen $\mathrm{SH}$, Chu $\mathrm{CH}$, Huang SY, Tzeng NS, et al: Comparing clinical responses and the biomarkers of BDNF and cytokines between subthreshold bipolar disorder and bipolar II disorder. Sci Rep 6: 27431, 2016. 